\title{
Climate Change, Rural Livelihoods and Ecosystem Nexus: Forest Communities in Agro-ecological zones of Nigeria
}

\author{
Olushola Fadairo, Samuel Olajuyigbe, Tolulope Osayomi, \\ Olufolake Adelakun, Olanrewaju Olaniyan, Siji Olutegbe, and \\ Oluwaseun Adeleke
}

\section{Contents}

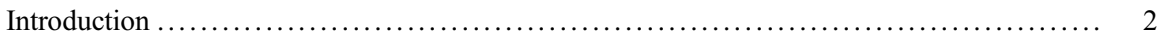

Forest Livelihoods and the Challenge of Changing Climate ...................... 4

Agriculture, Climate Change, and Food Security .............................. 6

Climate Change and Drivers of Social Vulnerability in Nigeria $\ldots \ldots \ldots \ldots \ldots \ldots \ldots \ldots \ldots, 6$

Theoretical Framework ................................................... 7

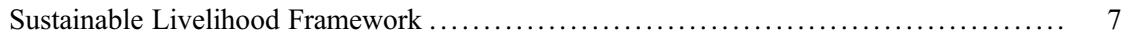

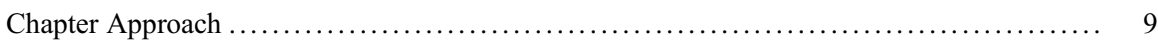

Effects of Climate Variability on Cropping Calendar in Mangrove, Rainforest, and Savannah Agroecological Zones of Nigeria ........................................... 13

Perceived Trend in Agriculture, Forest Area, and Population as Primary Drivers of Social Vulnerability .......................................................... 15

Perceived Effects of Drivers of Climate Change on Household Livelihood ............ 17

This chapter was previously published non-open access with exclusive rights reserved by the Publisher. It has been changed retrospectively to open access under a CC BY 4.0 license and the copyright holder is "The Author(s)". For further details, please see the license information at the end of the chapter.

O. Fadairo $(\bowtie) \cdot$ O. Adelakun $\cdot$ S. Olutegbe $\cdot$ O. Adeleke Department of Agricultural Extension and Rural Development, University of Ibadan, Ibadan, Nigeria

e-mail: dairom2@gmail.com; flakyonline@yahoo.com; siji004u@yahoo.com; aladeoluwaseun@yahoo.com

\section{S. Olajuyigbe}

Department of Forest Production and Products, University of Ibadan, Ibadan, Nigeria e-mail: lekito2001@yahoo.com

\section{T. Osayomi}

Department of Geography, University of Ibadan, Ibadan, Nigeria e-mail: osayomi@yahoo.com

O. Olaniyan

Department of Economics, University of Ibadan, Ibadan, Nigeria

e-mail: lanreolaniyan@yahoo.co.uk 
Causes and Consequences of Environmental Degradation in the Nigeria Agroecological

Zones ............................................................ 19

Farming Communities' Needs for an Enduring Adaptation to Climate Change in Nigeria ... 20

Conclusion and Recommendation ........................................... 21

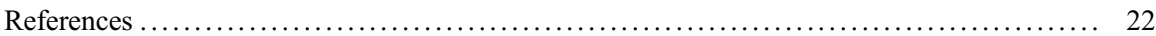

\section{Abstract}

A top-bottom approach where local problems are treated in isolation has proven ineffective in achieving sustainable development. The need for inclusive approaches to managing the demand for arable lands, forest resources, and the problems of resource exploitation and climate change calls for local understanding of these elements' interrelationship. Understanding the interrelationships among climate change, agriculture, and the ecosystems in different agroecological zones in Nigeria was the purpose of this chapter. Deforestation and forest degradation analysis approach was utilized. One state and two forest communities from each of the rainforest, savannah, and mangrove agroecological zones were purposively focused in this chapter based on forest distribution and cover. Focus group discussions involving 252 male and female farmers using 30 years as reference were used to garner relevant information. Climate variation caused a slight modification in cropping schedules of farmers due to prolonged dry season, mainly in the savannah region. Farmers engaged in mixed farming and also cultivate more hardy crops like cassava in response to climate uncertainties. Especially in the mangrove and savannah, ecosystem components such as agriculture and population showed increasing trends over the years as forest cover reduces. Downward trend in charcoal production was limited to mangrove and rainforest zones as fishing and hunting becomes vulnerable livelihoods across the zones. The degree and progression of climate change effects on the ecosystem in Nigeria agroecological zones is largely comparable and have both desirable and adverse livelihood outcomes. Affordable insurance policy, credit, agri-inputs, favorable forest regulatory framework, and youth empowerment supports would enhance sustainable adjustment to climate change.

\section{Keywords}

Forest communities $\cdot$ Cropping calendar $\cdot$ Agroecology $\cdot$ Climate change Vulnerability $\cdot$ Rural livelihoods $\cdot$ Nigeria

\section{Introduction}

Nigeria is seriously threatened by climate change with a significant proportion of its terrestrial ecosystem on dry land mass which is frequently affected by desertification, sheet erosion, and droughts. The coastal and mangrove agroecological zones in the south are also prone to incessant flooding because of their proximity to the Atlantic Ocean, riverine nature of the setting, the very low altitude, and all-yearround and high volume of rainfall. In recent times, variations in climatic conditions 
have resulted in undesirable effects on food production and nutritional security. Unfortunately, the country has very weak adaptive strategies and capacity to mitigate the effects of a changing climate. Presently, the impacts of rising temperatures and rainfall variability on farming are being felt across major agroecological zones in Nigeria (Ayanlade et al. 2018).

Agricultural systems are dependent on ecosystem services such as nutrient cycling, pollination, soil fertility, hydrological balances, and biological pest control which ensure a balance in the ecosystem (Power 2010). However, agricultural intensification in the last century has distorted the ecosystem equilibrium and led to loss of ecological integrity, land degradation, and loss of environmental services provided by the ecosystems. These conditions are further worsened due to increasing effects of climate instability (Pretty et al. 2011). For instance, environmental problems such as groundwater depletion, variability in the onset and amounts of rainfall, increase in concentration of greenhouse gases, soil degradation, depletion of pollinators' habitat, which all have negative consequences on sustainable agriculture, are climate change-induced.

Forest communities, which are highly vulnerable to these adverse effects, are occupied by low-income earners who depend on the ecosystem for their income, food, nutritional security, and livelihoods. Hence, these rural populations will be seriously affected by climate change, with little or no resources to adapt or mitigate its effects. It has been reported that the livelihoods of these communities are made vulnerable by land use variation such as continuous grazing and monoculture plantation. For example, in coastal and mangrove regions, there is a shortage of food resources obtained from streams coupled and agricultural instability due to increased flooding (Ward et al. 2016). Similarly, savannah and rainforest agroecosystems are recording a decline in agricultural production outputs (Ayanlade et al. 2018).

Natural resource utilization forms the base of most livelihoods in developing countries including Nigeria. However, forest resources are gradually being depleted due to the pressures of degradation and deforestation, poverty, urbanization, and poor management (Azeez et al. 2010; Saka et al. 2013). In Nigeria and most parts of Africa, shifting cultivation among small-holder farmers results in large-scale habitat destruction (Cooper et al. 2008). For instance, over $75 \%$ of the Nigerian population still lives in rural areas with vast areas of forest vegetation and depend on extensive rain-fed farming as well as short fallows for their sustenance. However, this dependence is limited by loss of forest biodiversity, climate change, and exposure of fragile soils (Azeez et al. 2010).

Frequent changes in climate parameters affect the livelihoods of rural populations and poses challenges to food security, survival, and economic development (Tompkins and Adger 2004). For instance, savannah and tropical forest zones have experienced a dramatic decrease in annual rainfall and an increase in the length of dry season and rainfall variability (Malhi and Wright 2004; Veenendaal and Swaine 1998). It is therefore pertinent to investigate the forest-dependent communities' responses to the hazards posed by climate uncertainties on their environment and livelihoods (Lindner and Pretzsch 2013), as this will have important implications for sustainable development in the near future. 
The capability of farming communities and agricultural stakeholders to manage the challenges and prospects of present climatic patterns must primarily be improved in order to enhance their adaptive capacity and reduce their exposure to the undesired effects of changing climatic conditions (Cooper et al. 2008; Tompkins and Adger 2004). The challenges are complex and call for integrative learning-oriented approaches that emerge from the bottom-up that will enable successful mitigation and adaptation. These approaches offer pathways for vulnerable communities to engage in developing response policies and ensure that there is room for change in those policies (Lindner and Pretzsch 2013).

Adaptive management is a cyclic, multiple stakeholder learning-oriented approach to the management of complex environmental problems such as climate change. The introduction of such approaches would encourage multi-stakeholder participation and the integration of all sectors in decision-making, policy formulation, and implementation (Stringer et al. 2006). Unfortunately, most policy implementers adopt a top-bottom approach where local problems are treated in isolation, and this method has proven to be ineffective in yielding or sustaining solutions. Therefore, the need for all-encompassing approaches to manage the demand for arable lands, forest resources, and the problems arising from resource exploitation and climate change (Lindner and Pretzsch 2013; Tompkins and Adger 2004). A step towards achieving this is to understand that the poor and vulnerable themselves are key actors in identifying important areas of their own livelihoods and solutions to their challenges.

For instance, rural communities have in times past developed indigenous technologies which have assisted in mitigating the risks associated with climate variability. These technologies are represented in local customs, traditions, and heritages, constituting a testimony of how societies have thrived well in various environments (Azeez et al. 2010; Vidaurre de la Riva et al. 2013). Therefore, research needs to integrate climate change impacts with sustainable agriculture in a stressed ecosystem. Such information will bridge the knowledge gap and assist planning for adapting and mitigating climate change. Therefore, this chapter explains how agriculture, climate change, and the ecosystems interrelate among themselves in the main agroecological zones of Nigeria. Specifically, this chapter discussed the effects of the changing climate on farming calendar and local adaptation measures employed, the trend in primary drivers of social vulnerability to climate variability, the drivers of vulnerability to climate variation as perceived by farmers, health and environmental effects of climate instability on forest communities in Nigeria, and forest inhabitants needs in services and or facilities for an effective adjustment to climate change.

\section{Forest Livelihoods and the Challenge of Changing Climate}

Forests are mainly situated in rural areas and/or frequently isolated areas (Aruwajoye and Ajibefun 2013). Apparently, such areas are in close harmony with nature with little development in terms of infrastructure (roads, potable water supply, markets, 
health facilities, and schools), government services, and jobs. Thus, it is not surprising that communities living in the fringe of these forests have limited livelihood opportunities and options (Wunder 2005). As a corollary to this, Bassey and Obong (2008) and Nayak et al. (2012) assert that communities around forest fringe are lowincome earners who sought to build their economic capacity by engaging in the livelihood options provided by the forest.

In Nigeria, more than $90 \%$ of the rural populace depend on forests for their livelihood (Ayuk et al. 2011; Fadairo et al. 2017). These livelihood activities offered by forests include hunting of animals, forest-based farming, timber logging, gathering of building materials, collection of fuel wood for cooking or charcoal production, materials for local craft, fodder (grasses and leaves for livestock and grazing of livestock), medicinal plants, and non-timber forest products which include honey, leaves, and fruits. Suffice it to say that these forest products derived from the various livelihood activities are not solely for household consumption but also for commercial purposes.

Studies have documented the benefits accruing from forest resources in the livelihood activities of those inhabiting the fringes of forests as substantial (Levang et al. 2005; Sunderlin et al. 2005). These benefits according to Warner (2000) are increased income, improved food security, reduced vulnerability by providing safety nets, and increased well-being. Furthermore, some of these livelihood activities have social, religious, and cultural dimensions. For instance, hunting may serve as a cultural event for initiation into manhood while fishing maybe a social or cultural event. In addition to this, Shackleton (2004) opine that forests provide sites for spiritual healing and religious practices. Hence, it is not uncommon to find sacred places, herbalists, and native doctors in forest communities.

Agriculture as an important livelihood activity in most forest communities is affected by climate change in several ways, namely, changes in rainfall, standard temperatures, and climate extremes (heat weaves). Climate change influences planting and cropping conditions which in turn affects the supply of food. It necessitates changes in farming methods, increases soil pressure, reduces water supply to the root system, and increases farmers reliance on agrochemicals for farming. In addition, crops stressed as a result of climate changes become more susceptible to damage from diseases and pests. Animal husbandry industry is also indirectly affected following climate-induced changes in the availability of grains, pasture, and forages and its accustomed price increase. Animals health are usually affected negatively by extreme heat (Enete 2014). Furthermore, peasant and small-holder farmers who produce the bulk of food consumed in most developing countries are usually vulnerable to climate uncertainties due to their small size of farms, poor technology, and little working capital (Morton 2007). In addition, the seasonal calendar which provides information on planting, sowing, and harvestings periods of locally adopted crops in specific agroecological zones (Fadairo et al. 2019) is distorted by climate variability, predisposing farmers to risks arising from weather uncertainties. 


\section{Agriculture, Climate Change, and Food Security}

The occurrence of climate change is interlinked with the performance of agriculture and attainment of food security. Agricultural production in most parts of Africa including Nigeria has been seriously affected by environmental degradation caused by climate change, making a case for serious intervention (Osuafor and Nnorom 2014). The current global climatic condition has both natural and man-made causes. The reliance on rain-fed agriculture by most African countries both as a source of income and consumption has resulted in their high vulnerability to climate change. Some of the devastating effects includes: erosion, flooding, drought, pests and diseases, desertification, gas emissions, fluctuation in rainfall patterns, and a host of others. These factors in turn impact on agriculture and consequently threaten food security. As a result, food security is at risk with a daily world population increase. In order to forestall the danger ahead, the United Nations has clearly set the targets of attaining food surplus, food security, and improved nutrition, and advancing sustainable agriculture as number two among its 17 Sustainable Development Goals (SDGs) for the year 2030.

According to Food and Agriculture Organization (2002) as cited by Coates (2013), food security exists when all individuals, at every time, have socioeconomic and physical access to adequate, nutritious, and safe food that meets their dietary requirements and food preferences for a healthy and productive life. Therefore, food security goes beyond having adequate supply of food but also include issues relating to the food safety and hygiene. For instance, use of chemicals such as fertilizer in planting or produce preservation as a response to climate fluctuation predisposes the population to poor health. This assertion is in line with Kinsey (2005) who opined that a nation is not regarded as food-secure just because food is available in the right quantity needed by its populace, but also when the food consumption does not predispose the people to any health hazard. In order to reduce the impacts of climate change on agriculture, various coping strategies have been put in place. Osuafor and Nnorom (2014) highlighted the strategies as including controlling greenhouse gases emission; preventing deforestation; planting climate-smart, disease-tolerant, and high yield crops; and adjustment of planting calendars by farmers.

\section{Climate Change and Drivers of Social Vulnerability in Nigeria}

In recent times, the variation in climate such as rise in temperature, increase in rainfall causing flood, delayed and inconsistent rainfall causing drought, strong wind, and landslides have threatened both the natural systems and the human society, specifically causing internal displacement of persons, destruction of lives, properties, and livelihood, food insecurity, disease outbreak, violence arising from struggle over resources, and increased suffering and penury. Yet, the impact caused by these climate extremes is not uniformly distributed among and within groups of people in the same country, state, and/or community (Petkova et al. 2015). Thus, it is unlikely for the impact of climate extremes to felt in the same way. Some groups 
or individual are likely to be more vulnerable than others. This underscores the need for researches to continually explore comparative analysis of climate change impacts across environmental, social, economic, and political factors in order to engender sustainable solutions.

In the views of Petkova et al. (2015), climate change effects will vary among age groups, sex, socioeconomic status, health condition, geographical location, and nature of livelihoods of the people. A measure of the extent of exposure of groups or individuals to stress as a result of the impacts of climate change extremes is known as social vulnerability. In this chapter, livelihood of the forest-edge communities in Nigeria is singled out among others for discussing the effects of vulnerability to climate change. Hence, stress in this perspective refers to the interference of the livelihood activities of groups or individuals in the face of climate extremes.

Evidence abounds that the people who are likely to be more susceptible to the adverse effects of climate extremes are people in the rural areas. Rural Nigeria is mainly agrarian with many of them living below the poverty line. Research reveals that rural communities are inexplicably vulnerable to climate extremes because their livelihoods are dependent on climate-sensitive activities (agriculture, forestry, fishing, recreation) in their rural environment (Fisher et al. 2013). Therefore, the effect of climate extremes poses a huge threat especially to the agrarian rural people many of whom already live below the poverty line.

\section{Theoretical Framework}

The Sustainable Livelihood Framework, as presented below, was considered relevant for underpinning the assumptions and approach utilized in this chapter.

\section{Sustainable Livelihood Framework}

Sustainable livelihood (SL) framework presents a tool for development workers to understand, analyze, and explain the real factors that affecting poor people's livelihood (Petersen and Pedersen 2010). According to Carloni and Crowley (2005), a livelihood comprises the assets (including both social and material endowments), capabilities, and activities necessary to earn a living. Ability to manage and recover from shocks and stresses, retain or enhance its assets and capabilities, while not depleting the natural resource base is what makes a livelihood sustainable. SL framework addresses the creation of guaranteed livelihoods for the poor by development workers. The basic principle of SL is that development work ought to focus on the people, with considerations of, what matters for the poor, cultural diversity, and its effects on livelihood processes. Secondly, poor people themselves are major actors in bringing about the change they desire. This is because they have a better knowledge of issues affecting them much more than any external person (Petersen and Pedersen 2010). The foregoing reechos the central argument in this chapter that adequate understanding of the perspectives of the local people whose livelihoods are 


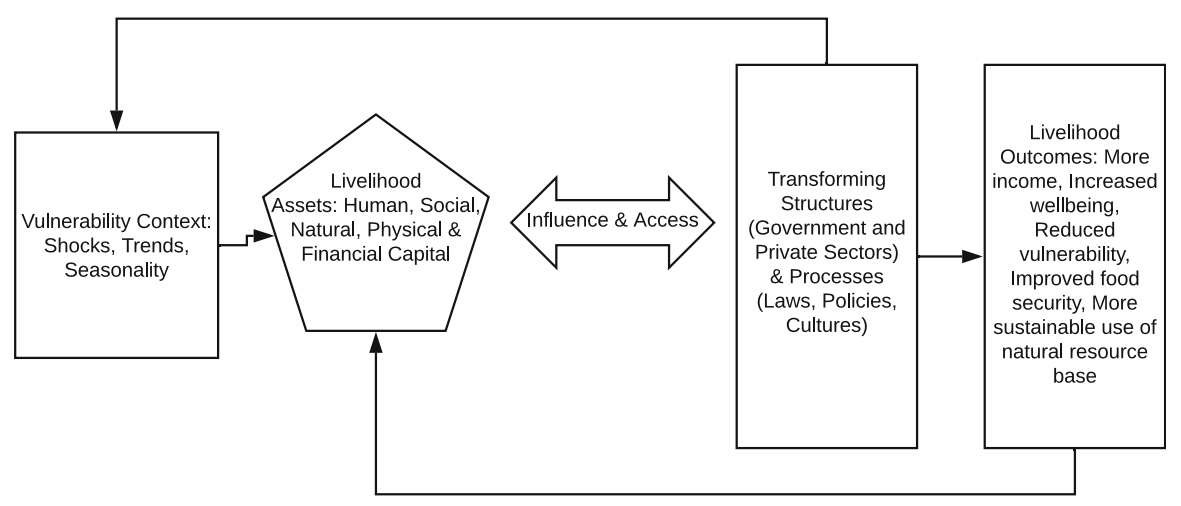

Fig. 1 Sustainable Livelihood Framework. (Source: DFID (2000), cited in Petersen and Pedersen (2010))

intertwined with and affected by climate variability is important for a more sustainable adaptation and mitigation measures for climate change. Hence, primary information used for discussion in this chapter were derived from engagement with those who are most affected in order to acquire their perspectives of their problems and what things to change to improve their condition. The key components of the SL framework are indicated in Fig. 1, and they include vulnerability context, livelihood assets, structure and process for transformation, livelihood strategies, and livelihood outcome.

Vulnerability context: This refers to people's external environment. It includes occurrences for which people have restricted or no control. Examples of such occurrences are critical trends of economic inflation, natural disasters, shocks, and seasonality, among others. The issue of vulnerability thus emerges when individuals are exposed to harmful threats they are not well equipped to confront (Petersen and Pedersen 2010).

Livelihood assets: Since the framework by nature focuses on the people, it thus seeks to have a better consideration of the people's power (capitals or assets). Since the approach relies on the belief that achieving livelihood outcomes requires a combination of assets, understanding how the conversion of the people's power to favorable livelihood outcomes becomes paramount. For this reason, the framework identifies five forms of capitals which support livelihoods. These are social, human, natural, financial, and physical capitals (Petersen and Pedersen 2010).

Structure and process for transformation: This refers to the establishments and regulations found from the household to the international levels that defines the livelihoods of the poor. These establishments and regulations stimulate how people access the various types of assets. Ownership rights and laws to secure individual rights are examples of processes, whereas structures are things like existence of ministries, banks with credit facilities for support groups and farmers (Petersen and Pedersen 2010). 
Livelihood strategies: This refer to the way in which people organize towards achieving their anticipated livelihood and access to diverse types of resources determine the approaches to be employed. Furthermore, societal opportunities or constraints can be dictated by its structures and processes.

Finally, livelihood outcome refers to the resultant effect of livelihood strategies assumed by the people. These effects could be better income, enhanced wellness, decreased susceptibility, and food security, among others (Petersen and Pedersen 2010).

\section{Chapter Approach}

This chapter utilized synthesis of literature and collection of primary data to reach its conclusions. The field activities for primary information garnering were carried out in Nigeria. Nigeria's ecological environment consists of seven agroecological zones such as saltwater swamp, freshwater swamp, Sudan savannah, guinea savannah, Sahel savannah, tropical rainforest, and the montane zones. However, discussions in this chapter are mainly focused on its three broadly classified agroecological zones namely savannah, mangrove/swamp, and rainforest. Each of these agroecological zones has their own peculiarities and supports a wide range of plant and animal species. Nevertheless, the tropical rainforest has been adjudged the richest. All adult residents in forest communities who are engaged in farming and or other forestbased livelihood activities were engaged in discussions. Adults who were 45 years and above at the time of the field work were specifically targeted due to the 30 years reference period used in this chapter. A two-stage sampling procedure was used. First, from each of the three major agroecological zones, one state was purposively sampled based on distribution and extent of forest cover. Second, two forest communities in each sampled state were selected purposively based on intensification of climate variability in the past 15 years. Thus, six forest communities namely Iyamitet, Ikom Agoi (Cross River State), Wawa-Gbere, Emi-Hakimi Mokwa (Niger State), Osoku, and Fowowa (Ogun State) were sampled for primary information garnering (Fig. 2). In each of the sampled locations, a short survey was carried out to generate a pool of potential participants for focus group discussions as follows:

\footnotetext{
Would you be willing to participate in a focus group discussion regarding climate change, rural livelihoods and other related issues? The discussion would take about 2-3 hours on . (date) and you would be incentivised for participation. The discussion will be audiotaped for the purposes of review by the researchers.

Yes [ ] No [ ]. Name............. Phone no...........

Age...................
}

Given the size of potential participants generated, four focus group discussions comprising 10-12 members per group were held in each forest community. Thus, qualitative data were collected from 24 focus group discussions held with 252 male 


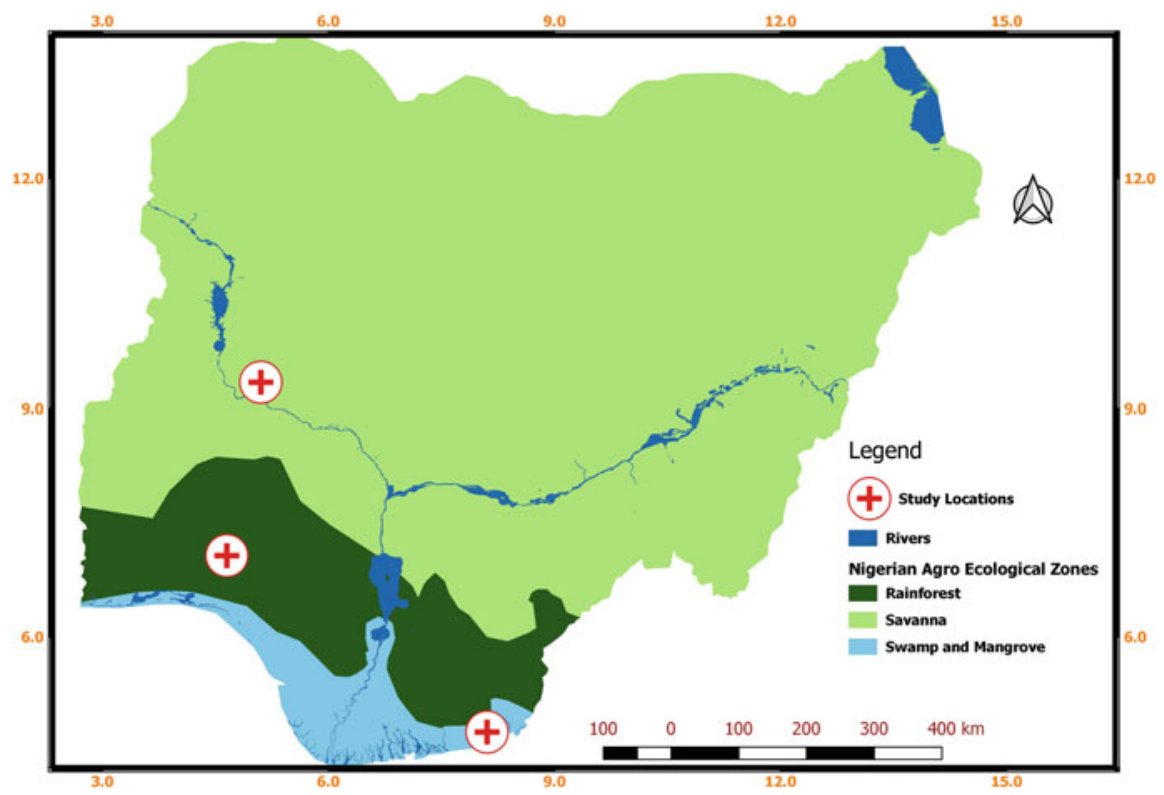

Fig. 2 Map showing the focus group discussion locations within the agroecological zones of Nigeria

and female farmers in selected sites. Deforestation and Forest Degradation Analysis adapted from Tiani et al. (2015) was used in this chapter. Using a discussion guide and 30 years as reference, primary information was sought on effects of climate change on farming calendar, trends in primary drivers of social vulnerability to climate change, causes and consequences of environmental degradation in forest communities, and communities needs in services and/or facilities for an effective adaptation.

A visual representation showing seasonal activities among community members on a flip chart was used to facilitate conversation on how climate change affects farming calendar. Discussants indicated their cropping pattern in a calendar year, the associated activities, and why the activities are conducted in order to provide information on farmers' local climate change adaptation measures. Also, participants during the discussions used pebbles (stones) to proportionately represent areas covered by each ecosystem components (population, agriculture, forest cover, hunting, and charcoal production) as perceived over the past 30-year period (Figs. 3, 4, 5, and 6). The outcome of this exercise was represented in a single table to indicate the trend as perceived by the discussants. Influence of climate change on local livelihood activities were captured by asking participants to award scores to represent magnitude and impact of each climate parameter on available livelihood activities. Problem tree analysis and paired needs ranking participatory tools were used to investigate health and environmental impacts of unstable climate on forest 
Fig. 3 Male participants during focus group discussion at Mokwa, Niger State on March 9, 2018

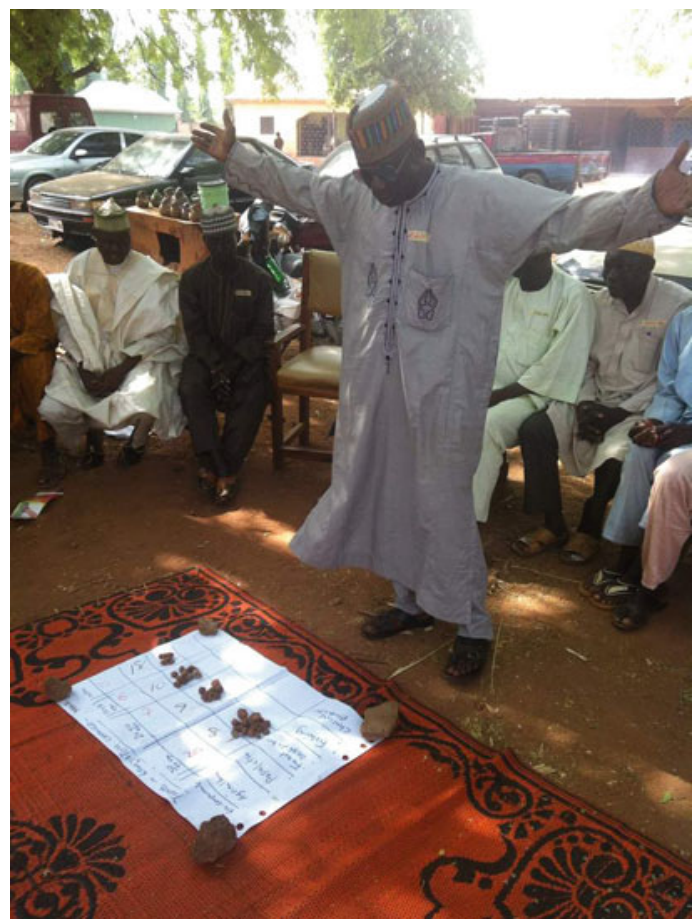

communities and communities needs in services and or facilities for an effective adaptation to climate change, respectively.

During the discussions, audiotape recording, flip chart, and handwritten notes were taken by researchers and were later transcribed. Primary information collected were coded and analyzed based on thematic patterns in the participants responses to issues raised in the focus group discussions. In doing this, particular attention was paid to important quotes from some of the respondents. Some of these quotes are used as evidences to support discussions in this chapter.

Limitations however exist in the approach used in this chapter due to language barrier experienced in some of the field locations as we observed that some respondents could not communicate well in the English language. Therefore, the researchers relied on translators to interpret the questions to the respondents and participants' responses back to the researchers. Some content and meaning may have been lost in this process. Also, due to the problems of insurgency, farmer-herdsmen conflict, and other security issues, most states within the savanna agroecological zone were deliberately excluded from the focus group discussions. 


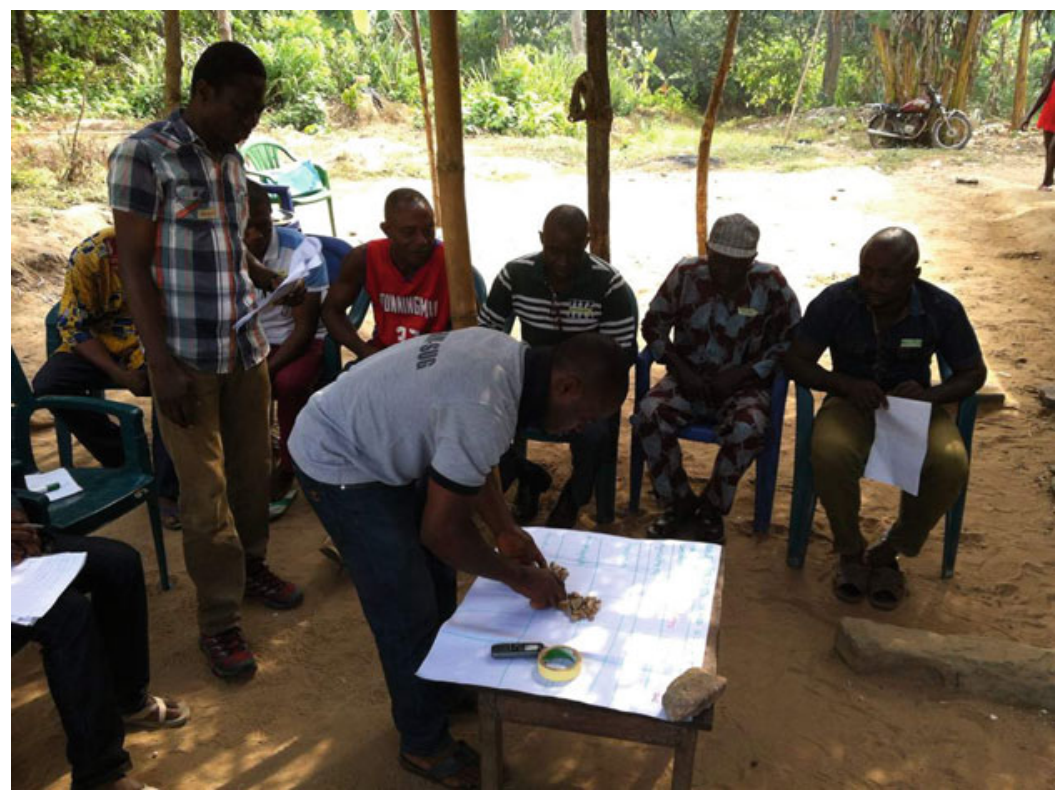

Fig. 4 Male participants during focus group discussions at Iyamitet, Cross River on 14 February, 2018

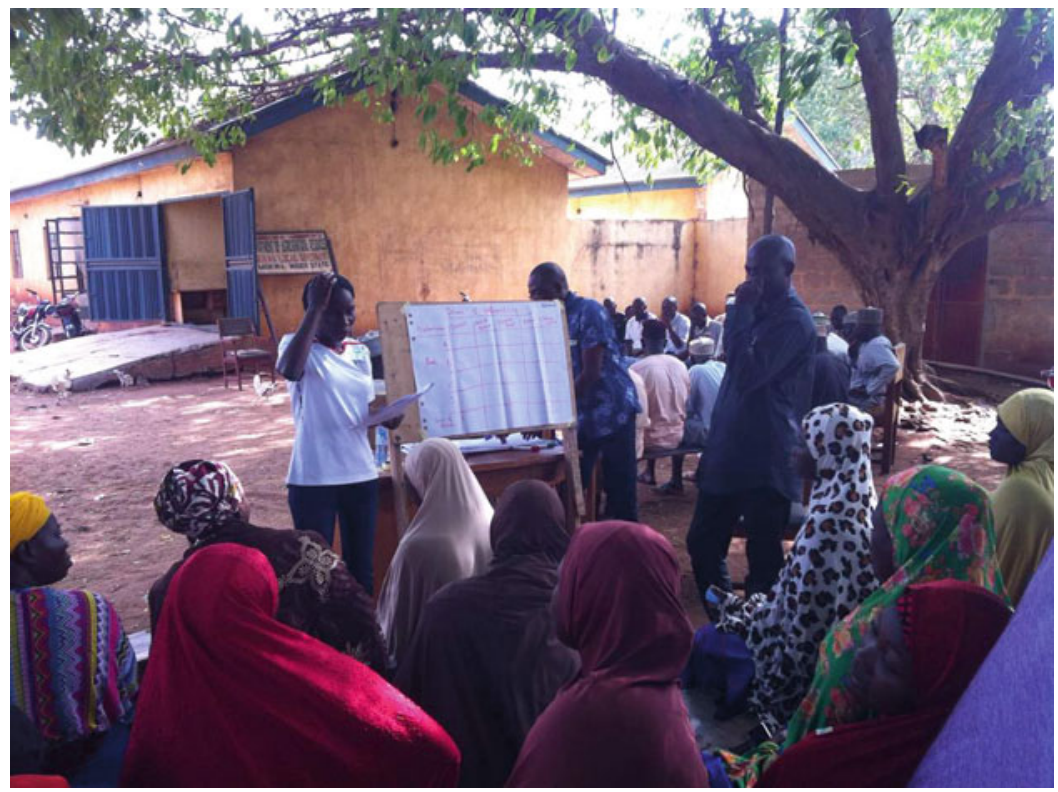

Fig. 5 Female participants at FGD at Mokwa on March 9, 2018 
Fig. 6 Female participants at FGD on April 11, 2018 at Osoku

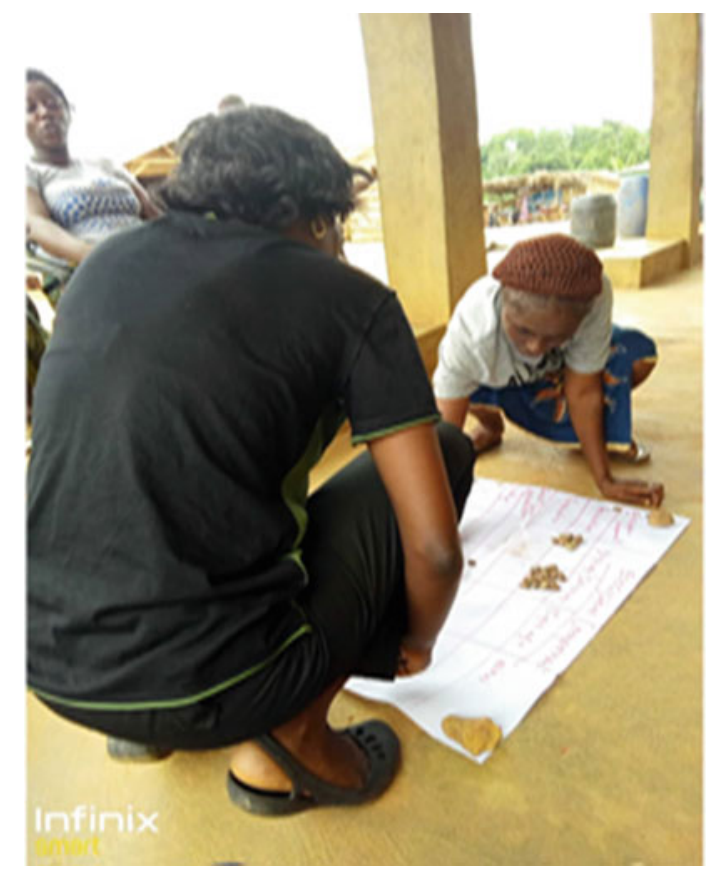

\section{Effects of Climate Variability on Cropping Calendar in Mangrove, Rainforest, and Savannah Agroecological Zones of Nigeria}

Farm households' ability to grow enough food to feed themselves and their animals is determined to a large extent by the weather since agricultural production depends on climate variables, such as temperature, precipitation, and light. Therefore, shifts in temperature and precipitation are important parameters for farming communities in the timely operations of farm operations. Table 1 shows the activities done in relation to the major crops produced by each of the ecological zones. Yam, cocoa, and maize were focal crops in the mangrove, rainforest, and savannah zones, respectively. Within the mangrove ecological zone, the major activity between January and May was land preparation, with dry and wet seasons being observed in March 30 years ago. Currently, there is a little shift, as dry and wet seasons are now being observed in April. It was clear that there is a relatively longer dry season now compared to what it was 30 years ago as wet season was fully experienced from April to September, lasting a period of 6 months. In the recent times, however, the wet season now occur in May to August, lasting only 4 months. This trend is similar to what is observed in the rainforest and savannah zones with extended dry season compared with the referenced 30 years ago. This shows a drop in the duration of rainfall across the three agroecological zones. This change in climatic trend is in line 
Table 1 Seasonal and cropping calendar for major crops in mangrove, rainforest, and savanna ecological zones of Nigeria

\begin{tabular}{|c|c|c|c|c|c|c|c|c|c|c|c|c|}
\hline & \multicolumn{12}{|c|}{ Months of the year (January-December, respectively) } \\
\hline & $\mathbf{J}$ & $\mathbf{F}$ & M & A & M & $\mathbf{J}$ & $\mathbf{J}$ & A & $\mathbf{S}$ & $\mathbf{O}$ & $\mathbf{N}$ & D \\
\hline \multicolumn{13}{|l|}{ Mangrove } \\
\hline Season 30 years ago & $\mathrm{D}$ & $\mathrm{D}$ & $\mathrm{D} / \mathrm{W}$ & W & $\mathrm{W}$ & $\mathrm{W}$ & $\mathrm{W}$ & $\mathrm{W}$ & W & $\mathrm{D} / \mathrm{W}$ & $\mathrm{D}$ & $\mathrm{D}$ \\
\hline Season currently & $\mathrm{D}$ & $\mathrm{D}$ & $\mathrm{D}$ & $\mathrm{D} / \mathrm{W}$ & W & W & W & W & $\mathrm{D} / \mathrm{W}$ & $\mathrm{D}$ & $\mathrm{D}$ & $\mathrm{D}$ \\
\hline \multicolumn{13}{|l|}{ Activities currently } \\
\hline \multicolumn{13}{|l|}{ - Land preparation } \\
\hline \multicolumn{13}{|l|}{ - Planting } \\
\hline \multicolumn{13}{|l|}{ - Weeding } \\
\hline \multicolumn{13}{|l|}{ - Staking } \\
\hline \multicolumn{13}{|l|}{ - Harvesting/storage } \\
\hline \multicolumn{13}{|l|}{ Rainforest } \\
\hline Season 30 years ago & D & D & $\mathrm{D} / \mathrm{W}$ & W & W & W & W & $\mathrm{W}$ & W & W & $\mathrm{D} / \mathrm{W}$ & D \\
\hline Season currently & $\mathrm{D}$ & $\mathrm{D}$ & $\mathrm{D}$ & $\mathrm{D} / \mathrm{W}$ & W & W & W & $\mathrm{W}$ & W & DW & DW & $\mathrm{D}$ \\
\hline \multicolumn{13}{|l|}{ Activities currently } \\
\hline \multicolumn{13}{|l|}{ - Land preparation } \\
\hline \multicolumn{13}{|l|}{ - Cocoa nursery } \\
\hline \multicolumn{13}{|l|}{ - Planting } \\
\hline \multicolumn{13}{|l|}{ - Weeding } \\
\hline \multicolumn{13}{|l|}{ - $\quad$ Spraying } \\
\hline \multicolumn{13}{|l|}{ - Harvesting/storage } \\
\hline \multicolumn{13}{|l|}{ Savanna } \\
\hline Season 30 years ago & $\mathrm{D}$ & $\mathrm{D}$ & $\mathrm{D} / \mathrm{W}$ & W & W & W & W & $\mathrm{W}$ & W & W & $\mathrm{W} / \mathrm{D}$ & $\mathrm{D}$ \\
\hline Season currently & $\mathrm{D}$ & $\mathrm{D}$ & D & $\mathrm{D}$ & W & W & $\mathrm{W}$ & W & W & $\mathrm{W} / \mathrm{D}$ & $\mathrm{D}$ & $\mathrm{D}$ \\
\hline \multicolumn{13}{|l|}{ Activities currently } \\
\hline - Land preparation & & & & & & & & & & & & \\
\hline - Planting & & & & & & & & & & & & \\
\hline - Weeding & & & & & & & & & & & & \\
\hline - Harvesting/storage & & & & & & & & & & & & \\
\hline
\end{tabular}

with the position of Appiah et al. (2018) that there is a decrease in the intensity of rain in most forest reserves communities of most sub-Saharan African countries where there is still heavy reliance on agriculture as primary means of livelihood. This change has implications for agriculture in Nigeria which is known to be mainly rainfed.

Further, two of the participants at focus group discussions gave explicit distinctions of the season and farming activities between 30 years ago and now as thus:

Thirty years ago, we experienced little rainfall in the month of March and then the rains become fully established in April and then fade away in September. Presently, we experience little rainfall in the month of February which become fully established in April and then fades out in October.

Land clearing of farmland in our area has shifted from January/February to March. This happens because onset of rain has shifted to April, currently any rain we see in February/ March is tagged accidental rain. 
Another discussant also said:

'Compared to thirty years ago, there is reduced intensity and duration of rainfall' (A 50-yearold man, Muslim, farmer, savannah zone).

Access to food through both production and exchange will continue to depend not only on the productivity and profitability of agriculture, but also on how well the political climate enables people to respond creatively to their environment and prospects. As a means of adapting to the extended dry spell, farmers have adopted the cultivation more hardy crops such as cassava to reduce economic losses associated with climate change. Diversification into trading and processing of agricultural produce also take place during the off seasons to bridge income gap that is now experienced. This corroborates the assertion of Appiah et al. (2018) which argues that farmers in forest communities are often engaged in other economic activities to supplement their agriculture-based incomes. One of the discussants said thus:

Presently, when there is no planting activity, we engage in other businesses like buying and selling so as not to be idle and to earn money.

\section{Perceived Trend in Agriculture, Forest Area, and Population as Primary Drivers of Social Vulnerability}

The relationship between climate change and ecosystem is intertwined. Climate change can affect the distribution and behavior of some ecosystem components. Conversely, the intensification of some ecosystem components such as forest cover also have implications for carbon sequestration capacity, and hence extent of climate change impact on the environment. In this chapter, element of the ecosystem such as agriculture, forest cover, population, and alternative income-generating activities in the sampled sites such as fishing, hunting, and charcoal production were focused for understanding the interrelationship among these elements and climate change. Across the three agroecological zones of rainforest, mangrove, and savanna, more people are presently involved in agricultural activities compared with 30 years ago. This, according to discussants, is due to lack of employment for graduates and irregularities in payment of salaries/wages to government workers. Therefore, the need for alternative sources of income or employment (for the unemployed) has caused the recent surge in the farming population in the areas. A 48-year-old woman farmer in one of the rainforest communities explained thus:

Very few people were involved in agriculture thirty years ago in our community, then, youth only engaged in land clearing, planting and weeding of their parents' farms. However, as our population increases many people got involved in agriculture and young people now cultivate their own farmlands. 
Population as a component of the ecosystem also witnessed increasing trend in the last 30 years in all the agroecological zones. Population is a key factor that differentiate Africa from other regions of the world. African population is projected to grow rapidly throughout the twenty-first century and this growth will have direct effect on the demands for agricultural commodities. Discussants explained that increase in population is caused mainly by two factors. First, migration of people into various communities within the area for livelihood, especially in agriculture. Rural areas are known to be rich in an important factor of production which is land. Second factor was increase in child-bearing and survival of children due to improved health awareness. However, while there was increase in population and intensity of agriculture across the agroecological zones, decrease in forest spread and abundance of non-timber forest products such as snails and mushrooms was observed across the zones in the last 30 years. This is caused by deforestation and bush burning, occasioned by increase in population. Increasing population exerts more pressure on resources leading to upsurge in the rate of felling of trees for cooking and charcoal production. Increasing involvement of people in agriculture and declining soil nutrient also led to agricultural "extensification" and the consequent expansion of land for agricultural activities. The implication is that more forest cover is removed in order to increase size of land cultivated for farming. A 52-year-old man in one of the savannah communities remarked during the focus group discussions as follows:

The forest cover has drastically reduced against how it was. In those days we usually have 10-2 stumps of tree together, but due to deforestation by saw millers, increase in land acquisition for farming activities and construction of houses, almost all the trees are gone.

Further, hunting and fishing activities have assumed a downward trend in the savanna, mangrove, and rainforest zones in the last 30 years. This can be attributed to a decline in their distribution in their natural habitat and hence, reduced motivation on the part of the hunters and fishermen to continue in the business due to low rewards. In addition, reduced trend in fishing activities in the locations is plausibly due to water pollution, overfishing, and reduction in water volume caused by prolonged drought and a decline in intensity and duration of rainfall. Idowu et al. (2011) confirmed a decline in Catch Per Unit Effort (CPUE) in coastal areas of Nigeria due to pressure of climate change. However, charcoal production is among the gradually becoming prominent livelihood activities in savannah and mangrove zones. This is perhaps as a replacement for fishing and hunting livelihood activities that are already becoming faded in the areas. Charcoal production serves as an alternative income source for farmers in rural communities while ignoring its longterm implications for a sustainable environment. This is consistent with Mwampamba (2007) who had projected that by 2028, public forest resources would be depleted in some parts of Africa and there would be a total collapse of charcoal chain if no measures are put in place to stop the trend. Mwampamba's position suggests that there is an arbitrary involvement in charcoal production and that the rate of growth in the sector is largely unsustainable. Massive charcoal production in the areas have implications for availability of None Timber Forest 
Table 2 Trend in ecosystem components as primary drivers of social vulnerability to climate change

\begin{tabular}{l|l|l|l|l|l}
\hline & & \multicolumn{4}{l}{ Index of intensification in last 30 years (\%) } \\
\cline { 2 - 6 } Agroecological zones & Ecosystem components & 1987 & 1997 & 2007 & 2017 \\
\hline Rainforest & Agriculture & 18.6 & 21.0 & 24.6 & 36.0 \\
\hline & Population & 25.0 & 20.6 & 21.6 & 33.6 \\
\hline & Forest cover & 44.6 & 24.6 & 19.6 & 11.6 \\
\hline & Fishing & 58.0 & 22.0 & 14.0 & 6.0 \\
\hline \multirow{2}{*}{ Mangrove } & Charcoal production & 100 & 0 & 0 & 0 \\
\hline & Agriculture & 18.5 & 21.0 & 24.5 & 36.0 \\
\hline & Population & 25.0 & 20.0 & 21.5 & 33.5 \\
\hline & Forest cover & 44.5 & 24.5 & 19.5 & 11.5 \\
\hline & Hunting & 56.0 & 24.0 & 14.0 & 6.0 \\
\hline \multirow{2}{*}{ Savanna } & Charcoal production & 92.0 & 0 & 0 & 8.0 \\
\hline & Agriculture & 21.0 & 15.5 & 20.5 & 43.0 \\
\hline & Population & 15.0 & 20.0 & 23.0 & 42.0 \\
\hline & Forest cover & 46.0 & 24.0 & 18.0 & 12.0 \\
\hline & Fishing & 38.0 & 20.0 & 20.0 & 22.0 \\
\hline & Charcoal & 4.0 & 9.0 & 19.0 & 68.0 \\
\hline
\end{tabular}

Products (NTFPs) in the area. During the focus group discussion, one of the discussants explained (Table 2):

Duration of time used for collecting products in the forest has reduced because of scarcity of these products in the forest. Harvest from NTFPs was much thirty years ago (A 45-year-old woman, Christian, farmer, rainforest zone)

\section{Perceived Effects of Drivers of Climate Change on Household Livelihood}

Weather patterns are becoming unpredictable due to increasing variability in climate parameters. Rising temperature and increased frequency of extremely dry and wet years are expected to slow progress in crop productivity, livestock system, and improved food security. This section explains the effects of drought, flood, pest and diseases, increase in temperature, and strong wind as observable drivers of vulnerability to climate change in the Nigeria agroecological zones. The effect of each was captured in both direction (negative or positive) and magnitude (which measures the extent of such effects) on subsistent crop, cash crop, charcoal production, and animal production. In the agroecological zones, the negative effects of drought were most felt on subsistence crops. Cash crops such as cocoa were not spared as the effect was high, especially on the field. An opinion leader among the farmers in Iyamitet community (mangrove zone) explained thus: 
In recent times, there is incessant invasion of pests and diseases on our crops which we cannot effectively control. Most times, it takes a lot of time before we understand the nature and causes of such infestation and able to adjust to it. The result is a serious reduction in the quality of our crops and huge losses for us. Ugly experience from the last year harvest has even discouraged some few cocoa farmers from business.

Discussions further revealed that charcoal production was the most resistant or the least affected by drought in the ecological regions. The reverse was the case with respect to flooding, as charcoal production was reportedly highly affected in terms of quality of charcoal, quantity of wood (log), and duration of activities of charcoal production. The level of vulnerability was also high for subsistent crops, cash crops, and availability of NTFPs. Discussants during the focus group sessions justified their position that flood has a high negative effect on charcoal production explaining that when flood occurs, it washes away the charcoal heaps and woods, thereby terminating the charcoal production process. The implication is that while flooding is not an everyday occurrence, the few times it occurs, it has considerable negative effect on the quantity, quality, and hence profitability of charcoal production among producers.

Furthermore, livestock production was the least threatened livelihood by increased temperature, with little or no observable implications for livestock/milk production. However, almost all the livelihood activities were threatened by increased temperature with negative implication for future and present income generation among the people. The effects of pests and diseases, which were also directly associated with climate change as reported earlier, is also evident on subsistent crop, NTFPs, and cocoa production. This rating agrees with the position of majority during discussions as they were unanimous that pests and diseases had grown in both frequency of occurrence and severity of effects in the past few years with observable negative effects on crops and other means of income generation. On the other hand, the effects were less felt on charcoal and livestock production.

The last driver considered was strong wind. This chapter reveals that strong wind had the least effect on respondent's various livelihood activities, with the most visible effects on NTFPs and the least on livestock production. The effect was rated moderate on charcoal production. This rating was backed by some explanations during discussion as follows:

Strong wind often has negative effect on quantity of charcoal produced. This is often due to strong wind and availability of opening on the charcoal heap. This causes air to enter the charcoal heaps. This occurrence often reduces production efficiency, leading to high ash to charcoal ratio, thereby reducing quantity and profitability of our charcoal production enterprise. 


\section{Causes and Consequences of Environmental Degradation in the Nigeria Agroecological Zones}

The problem tree analysis in Fig. 7 illustrates the composite results of the effects of environmental degradation in the three ecological zones. It gives the causes and effects of the common problem identified as environmental degradation. The causes of environmental degradation identified in this section are consistent with earlier discussions and include drought, deforestation, strong wind, delayed rainfall, bush burning, use of agrochemicals, and air pollution. This corroborates the report of Somorin (2010) that impact of climate change could be felt by increased temperature, deforestation, and drought. Discussants also reported that the effects of environmental degradation produced both adverse health and environmental consequences such as mental disorder, measles, meningitis, water scarcity, erosion, cough/catarrh, body pain, reduced NTFPs activities, erosion, poverty, low income and poor harvest, soil infertility, increased incidence of pest and diseases and fever.

Specifically, in savannah zone, respondents experienced strong wind which is carries particles of dust causing cough and catarrh. Idowu et al. (2011) established

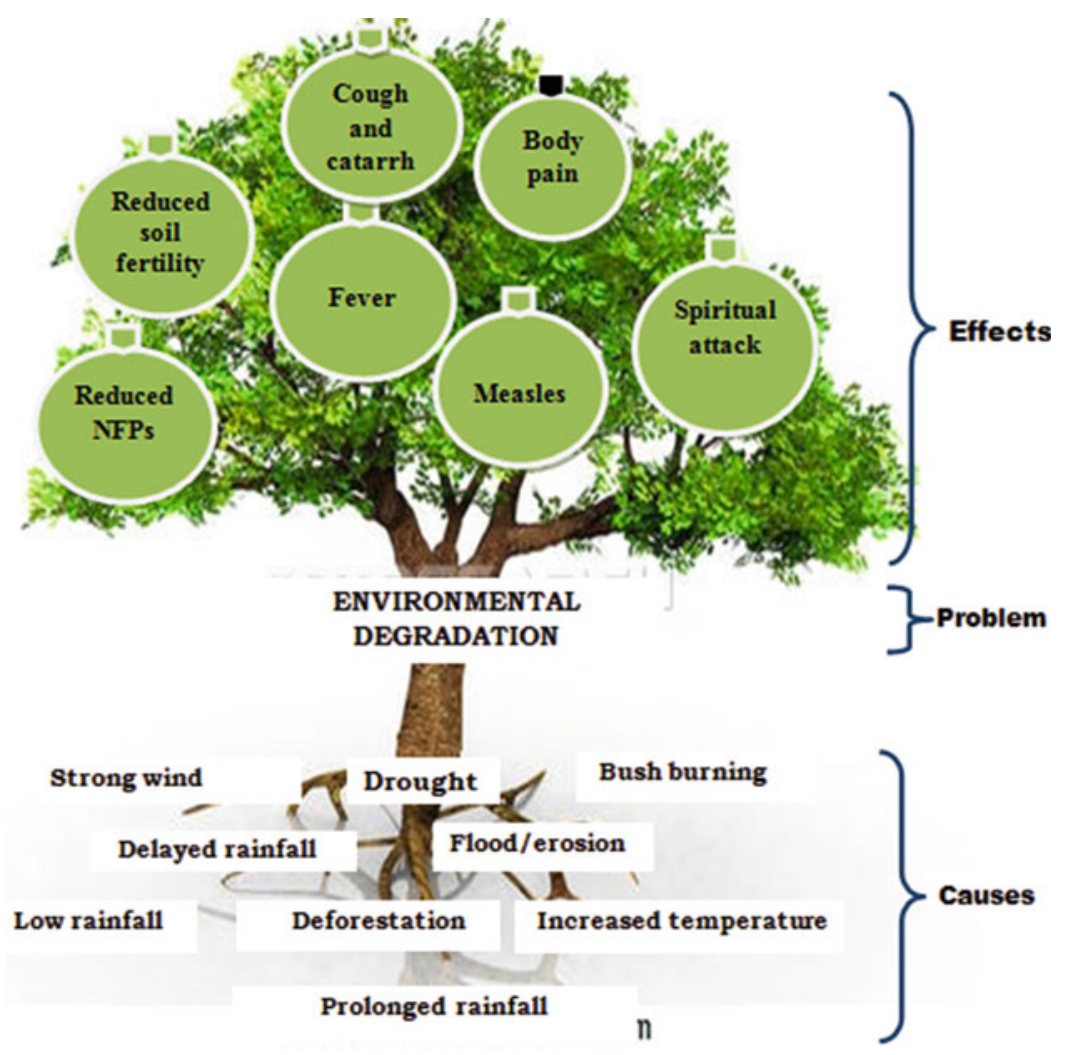

Fig. 7 Problem tree analysis of causes and consequences of environmental degradation in Nigeria 
that respiratory diseases and infections like cough and catarrh are prominent in harsh climate due to presence of pollutants and dust. Also, increased temperature in the area causes meningitis and measles which is very common in children of less than 5 years. A 37-year-old woman from savannah zone and 30-year-old lady from mangrove zone are quoted, respectively, as follows while commenting on the consequences of some of climate change parameters on their health and livelihoods:

During hot weather, as we now frequently experience here, there is usually the prevalence of meningitis, measles and chicken pox especially among our children. Also, wind is accompanied with dust, and this brings about occurrence of cough and catarrh is common. Increased temperature also affects our animals and crops as pests and diseases grow more when the weather is hot which slow down crop production (A 37-year-old woman, Muslim, farmer, savannah zone).

The impact of wind is low and it could be beneficial when drying crops after harvesting them. But when it is too strong, it could destroy the crops' (A 30-year-old woman, Christian, processor, mangrove zone)

An interesting link between deforestation and pervasiveness of mental disorder among the people was alluded to in Wawa community (savannah zone) where the participants argued that deforestation releases certain spirits which are believed reside in trees to inflict young ladies with insanity. One of the male discussants said the following:

Due to deforestation, spirits that abode in the trees are made homeless and therefore come to town and enter into our young ladies making them go insane. We are able to establish this because during deliverance session for some of the victims, the spirits confessed that their natural habitats have been disrupted and that's the reason for the attacks.

\section{Farming Communities' Needs for an Enduring Adaptation to Climate Change in Nigeria}

Farming communities' adaptation is key in translating climatic challenges and agricultural responses into changes in production, prices, food supply, and welfare. The potential for positive change for farming communities will increase if farmers are helped to adapt to climate variability. Table 3 therefore show the priority ranking of what communities in the agroecological areas adjudged as their needs to effectively adjust to climate changes impact. Across the ecological zones, respondents highlighted some needs that were important due to various problems and setbacks they encountered arising from climate change. Availability of credit facilities ranked first, suggesting lack of sufficient capital for various livelihood activities and effective climate change adaptation. Building of health center ranked second as most of the communities' lacked access to well-equipped health centers that can provide health care services. Farmers also require farm inputs in the form of herbicides, 
Table 3 Needs matrix as identified by communities in forest-edge communities in Nigeria

\begin{tabular}{l|l}
\hline Needs & Ranks \\
\hline Credit facilities & 1 \\
\hline Heath center & 2 \\
\hline Farm inputs - improved seed variety, fertilizer, herbicides & 3 \\
\hline Good road network & 4 \\
\hline Pipe borne water & 5 \\
\hline Power supply & 6 \\
\hline Irrigation & 7 \\
\hline Communication network & 8 \\
\hline
\end{tabular}

improved seed varieties, and fertilizer as the third ranked need. Perhaps, the need to easily connect outside communities for timely marketing of agricultural produce necessitated farmer's choice of good access-linking road. Discussions revealed that farmers find it difficult to sell their produce to right buyers due to poor state of farmto-market road. Instead, commodities were often sold to middle men at farm gate prices and hence, low profitability for the farmers. Other infrastructure such as pipe borne water, power supply, communication network was also mentioned as some of their pressing needs across communities in the agroecological zones. The huge infrastructural deficit in the sampled locations is indicative of the state of physical development in most of the forest-edge communities in Nigeria. This corroborates the earlier assertion by one of the discussants:

\footnotetext{
'We strongly desire credit facilities and good road network to enable us perform better in our farming activities and also for outsiders to come into our community and trade with us' (A 52-years-old man, Christian, farmer, rainforest zone)
}

\section{Conclusion and Recommendation}

This chapter concludes that the scale and direction of climate change impact on agriculture as the primary rural livelihood and other ecosystem components in Nigeria's agroecological zones is largely comparable and have both positive and negative consequences on rural sustenance. While climate change impact combined with some other economic factors such as unemployment have encouraged urbanrural migration, agricultural intensification, and livelihood diversification on the one hand, it has increased vulnerability tendencies of rural households in forest-edge communities in all the agroecological zones of Nigeria on the other hand. Among several others, increased forest encroachment, lack of a well-coordinated policy framework which allows for alternative livelihood without accompanying forest regulatory framework were major vulnerability exacerbating factors for the rural poor. Although the rural populace need help for better adjustment to climate change, they also do have demonstrated ability to respond to changes occasioned by climate 
variability and are exploring these abilities to the best of their knowledge. Support in the form of affordable insurance policy, credit, agri-inputs, favorable forest regulatory framework, and youth empowerment would enhance sustainable adjustment to climate change among the rural people.

Acknowledgments This work was supported by the African Development Bank and Japan Trust Fund under the Education for Sustainable Development in Africa (ESDA) project on knowledge creation, sharing, and exchange between Asia and Africa in support of Sustainable Development of Africa.

\section{References}

Appiah DO, Akondoh ACK, Tabiri RK, Donkor AA (2018) Smallholders farmers' insight on climate change in rural Ghana. Cogent Food and Agriculture 4:1-16. http://www.congentoa. com/article/10.1080/23311932.208.1436211.pdf/27/April/2018. Assessed 17 June 2018

Aruwajoye AS, Ajibefun IA (2013) Assessment of livelihood strategies among households in forest reserve communities in Ondo state, Nigeria. Int J Sci Eng Res 4(7):1650-1655

Ayanlade A, Radeny M, Morton JF, Muchaba T (2018) Rainfall variability and drought characteristics in two agro-climatic zones: an assessment of climate change challenges in Africa. Sci Total Environ 630:728-737

Ayuk ET, Fonta WM, Ichoku HE (2011) Forest income and household welfare in rural Nigeria. https:/unu.edu/publications/articles/forest-income-and-household-welfare-in-rural-nigeria. html\#info. Accessed 20 Nov 2019

Azeez IO, Ikponmwonba OS, Popoola L, Amusa TO (2010) Land use activities among forest environments' dwellers in Edo State, Nigeria: implications for livelihood and sustainable forest management. Int J Soc For 3(2):164-187

Bassey BJ, Obong LB (2008) The role of non-timber forest products (NTFR) in community livelihoods: a case study of Okiro, Obudu Local Government Area Cross River state, Nigeria. J Environ Res Policies 3:98-105

Carloni AS, Crowley E (2005) Rapid guide for missions: analysing local institutions and livelihoods. Food and Agriculture Organization of the United Nations (FAO), Rome

Coates J (2013) Build it back better: deconstructing food security for improved measurement and action. Global Food Secur 2(3):188-194

Cooper PJM, Dimes J, Rao KPC, Shapiro B, Shiferawa B, Twomlow S (2008) Coping better with current climatic variability in the rain-fed farming systems of sub-Saharan Africa: an essential first step in adapting to future climate change. Agric Ecosyst Environ 126:24-35

Vidaurre de la Riva M, Lindner A, Pretzsch J (2013) Assessing adaptation - climate change and indigenous livelihood in the Andes of Bolivia. J Agric Rural Dev Trop Subtrop 114(2):109-122

Enete IC (2014) Impacts of climate change on agricultural production in Enugu State Nigeria. J Earth Sci Clim Change. https://doi.org/10.4172/2157-7617.1000234

Fadairo OS, Calland R, Mulugetta Y, Olawoye JE (2017) A corruption risk assessment of reducing emissions from deforestation and forest degradation project in Nigeria. Int J Clim Change Impact Responses 10(1):1-22

Fadairo O, Williams PA, Nalwanga FS (2019) Perceived livelihood impacts and adaptation of vegetable farmers to climate variability and change in selected sites from Ghana, Uganda and Nigeria. Environ Dev Sustain. https://doi.org/10.1007/s10668-019-00514-1

Fisher PA, Paveglio T, Carroll M, Murphy D, Brenkert-Smith H (2013) Assessing social vulnerability to climate change in human communities near public forests and grasslands: a framework for resource managers and planners. J For 111(5):1-9. https://doi.org/10.5849/jof.12-091

Idowu AA, Ayoola SO, Opele AI, Ikenweiwe P (2011) Impact of climate change in Nigeria. Iranica J Energy Environ 2(2):145-152 
Kinsey J (2005) Will food safety jeopardize food security? Agr Econ 32(s1):149-158

Levang, P., Dounias, E. \& Sitorus, S. (2005). Out of the forest, out of poverty? Forests, trees and livelihoods, 15(2): 230

Lindner A, Pretzsch J (2013) An international network on climate change impacts on small farmers in the tropical Andes - global conventions from a local perspective. Sustain Agric Res 2 (2):92-98. https://doi.org/10.5539/sar.v2n2p92

Malhi Y, Wright J (2004) Spatial patterns and recent trends in the climate of tropical rainforest regions. Philos Trans Biol Sci 359:311-329

Morton JF (2007) The impact of climate change on smallholder and subsistence agriculture. PNAS 104(50):19680-19685

Mwampamba TH (2007) Has the woodfuel crisis returned? Urban charcoal consumption in Tanzania and its implications to present and future forest availability. Energy Policy 35 (8):4221-4234

Nayak BP, Kohli P, Sharma JV (2012) Policy brief: livelihoods of communities and forest degradation in India: issues for REDD ${ }^{+}$policy. Https://www.semanticscholar.org/paper/Liveli hood-of-local-communities-and-forest-in-India-Nayak-Kohli/ 4a45c80a48147a4c607b96905212d6bf5f5622f6. Accessed 17 Nov 2019

Osuafor AM, Nnorom NR (2014) Impact of climate change on food security in Nigeria. Int J Sci Technol 3(1):1-16

Petkova EP, Ebi KL, Culp D, Irwin R (2015) Climate change and health on the U.S. Gulf Coast: public health adaptation is needed to address future risks. Int J Environ Res Public Health 12:9342-9356

Petersen EK, Pedersen ML (2010) The sustainable livelihoods approach: from a psychological perspective. Institute of Biology, University of Aarhus

Power AG (2010) Ecosystem services and agriculture: trade-offs and synergies. Philos Trans R Soc 365:2959-2971. https://doi.org/10.1098/rstb.2010.0143

Pretty J, Toulmin C, Williams S (2011) Sustainable intensification in African agriculture. Int J Agric Sustain 9(1):5-24

Saka MG, Jatau DF, Olaniyi WA (2013) Status of indigenous tree species in Girei forest reserve of Adamawa State. J For Res Wildlife Environ 5:28-40

Shackleton CM (2004) Assessment of livelihoods importance of forestry, forests and forest products in South Africa. Rhodes University, Grahamstown

Somorin OA (2010) Climate impacts, forest-dependent rural livelihoods and adaptation strategies in Africa: a review. Afr J Environ Sci Technol 4(13):903-912

Stringer LC, Dougill AJ, Fraser E, Hubacek K, Prell C, Reed MS (2006) Unpacking “participation" in the adaptive management of social-ecological systems: a critical review. Ecol Soc 11(2):39. http://www.ecologyandsociety.org/vol11/iss2/art39/. Assessed 12 July 2018

Sunderlin W, Angelsen A, Belcher B, Burgers P, Nasi R, Santose L, Wunder S (2005) Livelihoods, forests and conservation in developing countries: an overview. World Dev 33(9):1383

Tiani AM, Besa MC, Devisscher T, Pavageau C, Butterfield R, Bharwani S, Bele M (2015) Assessing current social vulnerability to climate change: a participatory methodology (Working paper no. 169). Center for International Forestry Research, Bogor. ISBN 978-602-1504-70-3. https://doi.org/10.17528/cifor/005463

Tompkins EL, Adger WN (2004) Does adaptive management of natural resources enhance resilience to climate change? Ecol Soc 9(2):10. http://www.ecologyandsociety.org/vol9/iss2/art10. Assessed 17 Aug 2018

Veenendaal EM, Swaine MD (1998) Limits to tree species distribution in lowland tropical rainforests. In: Newbery DM, Prins HHT, Brown M (eds) Dynamics of tropical communities. Blackwell Publishing, Oxford

Ward RD, Friess DA, Day RH, Mackenzie RA (2016) Impacts of climate change on mangrove ecosystems: a region by region overview. Ecosyst Health Sustain 2(4) 
Warner K (2000) Forestry and sustainable livelihoods; what part can forest and forestry play in reducing poverty? Unsilver: FAO, 51(202), 3-12

Wunder S (2005) Forestry and sustainable livelihoods. World Commission on Environment and Development (1999). Our Common Future. Oxford University Press, pp 1817

Open Access This chapter is licensed under the terms of the Creative Commons Attribution 4.0 International License (http://creativecommons.org/licenses/by/4.0/), which permits use, sharing, adaptation, distribution and reproduction in any medium or format, as long as you give appropriate credit to the original author(s) and the source, provide a link to the Creative Commons license and indicate if changes were made.

The images or other third party material in this chapter are included in the chapter's Creative Commons license, unless indicated otherwise in a credit line to the material. If material is not included in the chapter's Creative Commons license and your intended use is not permitted by statutory regulation or exceeds the permitted use, you will need to obtain permission directly from the copyright holder.

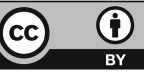

